\title{
Plasma spraying: present and future
}

\author{
P. FAUCHAIS, M. VARDELLE \\ University of Limoges - LMCTS - Equipe "Plasma, Laser, Matériaux" \\ URA 320 CNRS
}

123, Avenue Albert Thomas - 87060 Limoges Cedex - France

\section{ABSTRACT}

In this paper are presented successively : the general behaviour of the spraying plasma jets and how to characterize them, the different plasma torches which can be used, the plasma-particle interactions (modelling and measurements) and the influence of the surrounding atmosphere, the parameters controlling the way the particles flatten and the resulting splats cooling down, the way the coatings are built with the influence of the temperature control on the coating adhesion and residual stresses, the new technologies such as reactive plasma spraying, thermal plasma CVD...

\section{INTRODUCTION}

Plasma spraying is part of thermal spraying which is a group of processes in which finely divided metallic and non metallic materials are deposited in a molten or semi-molten state on a prepared substrate to form a spray deposit [1,2]. In this process the substrate can be kept at relatively low temperature by specific cooling devices. In fact thermal spray has been practiced since the early 1900 's [3]. Historically a surfacing technology, it has now moved from coating to materials processing technology with growing importance as stated by Smith [4]. DC plasma spraying, first proposed by Reineke in 1939 [4], was advanced in the late 1950's by several US companies. The high gas velocity DC arc torches were developed in the early 1970's by Pratt and Whitney with the Gator Gard (licenced to Sermatech [5]) and in the late 1980's by Browning with the high energy, high velocity Plazjet (licenced to a Japanese company [6]). The first spraying RF induction plasma torch, producing very low gas velocities, was reported in 1985 by Boulos and his co-workers [7] and then commercially developed by Tafa and Tekna in North America. Plasma spraying was pushed by the development of its applications (wear protection, thermal insulation or barriers, oxidation protection, corrosion resistance, abradable seals, abrasive surfaces or seals, electrically conductive or insulating materials, dimensional restoration or manufacture, medical implants... [1,2,4]). It is now part of engineering technology and a recent economical study [8] indicated that the world market of thermal spray was about 0.8 billion US\$ in 1991 (with 50\% for North America), plasma spraying representing (depending on the sources) 40 to $60 \%$ of this market. This market is poised for substantial growth in the next decade [9]. In plasma spraying many parameters need to be adjusted (about 60 macroscopic ones) and it makes the tasks of optimization and process control difficult. Manufacturing systems control the plasma spray process on previous experience in establishing a good coating without a fundamental understanding of what occurs. A few years ago, commercial integrated computer-controlled motion/process systems have shown up with closed-loop control of all operating parameters [10]. Moreover statistical optimization methods [11] are often used to optimize the coating properties. However a better control of plasma sprayed coatings quality and reproducibility needs fundamental studies. The purpose of this paper is to summarize what is our actual knowledge in this field, to present new technologies and try to forsee the potential developments. 


\section{SPRAYING PLASMA TORCHES AND THEIR CHARACTERISTICS}

\section{General behaviour of the plasma jets}

The characterisation of the plasma jets is not simple [12 to 16]. For example a technique widely used a few years ago and well automatized : emission spectroscopy of atomic lines, based on LTE assumption, overestimates the temperatures especially in the jet fringes. The techniques used to measure the heavy species temperature (which is that to be considered for momentum and heat transfer) : emission spectroscopy of rotational spectra, CARS (for which diatomic molecules are necessary), Rayleigh scattering and enthalpy probes, are limited to $\mathrm{T}<10000 \mathrm{~K}$. Thus reliable and fast temperature measurements are a problem, while velocity measurement methods, which were scarce and difficult, are now possible almost routinely using either the natural fluctuations of the arc root [17] or laser scattering [15] or enthalpy probes [16].

The large velocity difference between the plasma jet and the cold surrounding gas causes largescale eddies and the onset of turbulent flow $[13,19]$. This results in a large scale engulfment or entrainment of external atmosphere, the pumped quantity increasing with the flow velocity and decreasing when the viscosity of the mixture increases [20,21].

The engulfment type process results in the pumping of cold "bubbles" of surrounding gas which, due to their high density, are not mixed instantaneously with the plasma gas [13]. In air (atmospheric plasma spraying : APS) the cooling down of the plasma jet, due to oxygen dissociation at $3500 \mathrm{~K}$ at $10^{5}$ $\mathrm{Pa}$ [22], is much faster than when spraying is performed in nitrogen or even better in argon [23]. When reducing the pressure in a controlled atmosphere chamber the pumping is also reduced, the jet becomes longer but below about $30 \mathrm{kPa}$ its temperature is drastically reduced (down to $4000-5000 \mathrm{~K}$ at $12 \mathrm{kPa}$ ). Below 20 to $15 \mathrm{kPa}$ the jet becomes supersonic with shock-waves inducing particle injection and heat transfer problems.

At last, for the plasma jets produced by DC arcs, the anodic arc root attachment is continuously fluctuating resulting in surging and whipping motion of the plasma jet $[19,24]$. The frequencies of these fluctuations range from $2 \mathrm{kHz}$ to about $10 \mathrm{kHz}$. The resulting pulsing flow corresponds to jet lengths which may vary in a ratio higher than 2 participating to the surrounding atmosphere pumping. Many techniques have been used to try to control the arc length and reduce its fluctuations by fixing the arc root at a given area such as the use of segmented anode [25] or anode with step change in its diameter. However segmented anode adds complexity and is very rarely used in commercial torches [26]. Other tricks can be used such as boundary layer bleed holes [27].

Plasma jets laminar in their core, turbulent in their fringes with an engulfment type entrainment mechanism altering their chemical composition, which can also be modified by demixing of the plasma gases [16], are not simple to model [28,29] even when neglecting the arc fluctuations. More detailed and accurate turbulence models will be required to achieve satisfactory accuracy in the simulation of complex plasma flows.

\section{Conventional plasma torches}

The design of conventional plasma torches (CPT) has not much evolved since the beginning. They all consist of a stick type thoriated tungsten cathode followed by a water cooled copper anode nozzle [30]. The designing art consists in adapting the cone angle of the tip of the cathode to the arc current, the gas injection (axial, vortex...) the nozzle diameter ( 6 to $8 \mathrm{~mm}$ ) and shape. All the commercial plasma torches have the same common feature : for given gas nature and nozzle diameter the range of variations of arc current and gas flowrate is rather limited. The arc current increase does not change very much the temperature of the plasma jet ( 12000 to $14000 \mathrm{~K}$ at the nozzle exit for $\mathrm{Ar}-\mathrm{H}_{2}$ jets) but only slightly raises the plasma jet length and diameter [30] and it raises (from 1000 to $2200 \mathrm{~m} / \mathrm{s}$ ) the flow velocity ( $v^{2} \sim$ jet enthalpy) [17]. When the total gas flowrate increases, it seems that the velocity tends to 
a limit depending on the nozzle diameter [17]. However, when the nozzle shape is adapted, supersonic flows can be obtained.

\section{High power vlasma torches}

High power (200-250 kW) vortex stabilized plasma torches have been used for spraying since the fifties with water plasmas [31] and recently high power plasma torches (HPPT) operating with gases at 200-250 kW [32] have shown up. They work with a button type cathode, an efficient vortex, a long nozzle (125 mm) which diameter is 8 to $10 \mathrm{~mm}, \mathrm{~N}_{2}$ gas flowrates between 200 and 300 slm and $\mathrm{H}_{2}$ up to $150 \mathrm{slm}$, arc current up to $500 \mathrm{~A}$ and voltage, up to $400 \mathrm{~V}$, powder flowrates up to $20-30 \mathrm{~kg} / \mathrm{h}$. The enthalpy is lower than with the CPT, the mean temperatures of the jet is below $8000 \mathrm{~K}$ compared to CPT and thus the gas density is more than twice higher. It is claimed [61,32], that such torches improve coating density as well as bond strength owing to the increased kinetic energy of the particles.

\section{Torches with particle iniection in the arc column}

To improve the heat transfer to the particles, the particles can be injected in the arc column itself. This is the case of hollow cathode torches [30,33], of a torch where the anode is made with two small plasma jets produced by two torches ( $2 \mathrm{~kW}$ each) and where the voltage can reach $300-350 \mathrm{~V}$ for $\mathrm{I}=300$ A [34] and a torch using three cathodes set at 120 degrees around the torch axis, each one making an angle of 20 degrees with respect to the torch axis, the powder being injected axially before the three cathodes. However none of them is commercialized.

\section{RF plasma torches}

Inductively coupled plasma torches (ICPT) are characterized by their large volume (chamber diameter between 20 and $50 \mathrm{~mm}$ ) which, for power levels similar to those used in DC spraying torches (20-60 kW), results in much lower gas velocities (below $200 \mathrm{~m} / \mathrm{s}$ ) and energy densities (temperatures below $9000 \mathrm{~K}$ ). They can be operated with an inert, reducing or oxidizing atmosphere over a wide range of conditions with spraying chamber pressures ranging from 10 to $200 \mathrm{kPa}[7,36]$. The particles are injected axially with a water cooled injector. Their main advantage is the possibility of melting larger particles than typically possible using DC spraying conditions [36] $(\mathrm{d} \sim 100 \mu \mathrm{m})$. The torch being not movable the spray pattern has to be achieved by moving the substrate.

\section{Controlled atmosnhere}

Controlled atmosphere (CA) or soft vacuum spraying (VPS) improve coating quality and bond strength of sprayed materials very sensitive to oxidation. This is due to the possible high temperature regulation of both substrate and coating and minimal changes in the spread material no oxidation for example. This leads to closer control of the composition and morphology of sprayed coatings, demonstrated by a greater structural homogeneity, absence of oxides and improvement in hardness, thickness capability and deposition efficiency. However when using such equipments the capital cost increases considerably (in a ratio of one to two orders of magnitude) according to the complexity of such systems for industrial production [37]. The pressure of the CA chamber has to be adjusted to the material to be molten through trial and error tests or computer models [38]. For example if superalloys are sprayed at $15-20 \mathrm{kPa}$ the refractory carbides need to be sprayed at $105 \mathrm{kPa}$ in $\mathrm{Ar}$ atmosphere to benefit of the good heat transfer [23] and even sometimes at higher chamber pressure (200 kPa) [39].

\section{Nozzle shrouds}

To avoid the cost of the CA chambers, it has been imagined to use water-cooled protection nozzles to prevent the plasma jet flowing in air to mix with its surroundings. Nozzle shrouds [40] are especially designed to avoid low pressure regions close to the walls in order to avoid a counter current flow entraining the air. Such nozzles, which consume part of the torch energy (10 to 30\%) improve the 
particle melting but also increase their velocity [41] and are commercially used with HPPT for example to spray superalloys [42] with a low oxidation level.

\section{Underwater plasmaspraving}

This process, using an APS conventional plasma torch with an especially designed nozzle, runs completely underwater and exhibits new characteristic features [43] : short spraying distance (due to the jet quenching by water), good base material cooling allowing to spray on plastics, high pass thicknesses, high adhesion (similar to welding). This technique is mainly aimed at repair, maintenance and new part production for stationary components located underwater. However when the depth increases over $20 \mathrm{~m}$ the working conditions of the torch at higher pressure have to be improved.

\section{PLASMA PARTICLE INTERACTIONS}

To characterize the particles in flight in the plasma jets, many statistical techniques based on laser scattering (velocity, diameter, number flux) and two color pyrometery (particle surface temperature outside the plasma jet core) have been developed (see the reviews given in [12] and [14]). It is now possible to combine results of the gas flow and temperature fields with in flight particle parameter data [44]. However the interpretation of the results is difficult because the measurement volumes are not necessarily the same. Moreover the wide dispersion of the particle trajectories makes the problem very complex : inside the injector the carrier gas has a velocity distribution, the particles have a size distribution and moreover they undergo collisions with the injector wall resulting in a radial component of velocity which is the higher for the smaller particles [45]. With DC plasma torches the particles are injected orthogonally to the jet, sometimes with a second injector opposited to the first one to improve their trajectories [46]. A mean trajectory is adjusted by varying the carrier gas flowrate (according to the plasma jet momentum) [45]. But it is worth to underline that when using axial injection (hollow cathode [30] or RF plasma torch [7]) a broad trajectory distribution is also obtained.

The heat and momentum transfer to a particle [47] depend on its residence time and on the nature of the gas used (mostly $\mathrm{Ar}-\mathrm{H}_{2}$ and $\mathrm{Ar}-\mathrm{He}$ ) [21]. For example ternary mixtures $\left(\mathrm{Ar}-\mathrm{He}-\mathrm{H}_{2}\right.$ ) are used to improve both the heat transfer and the length of the plasma jet [48]. High heat transfer gases, such as Ar$\mathrm{H}_{2}$, enhance the heat propagation phenomenon with low thermal conductivity particles such as $\mathrm{ZrO}_{2}$ $[49,50]$. The residence time is linked to the plasma torch used. With CPT the melting of the most refractory particles is achieved with $\mathrm{Ar}-\mathrm{H}_{2}$ mixtures (at least $20 \mathrm{vol} \% \mathrm{H}_{2}$ ) provided that their size is below $50 \mu \mathrm{m}$ [45]. On the contrary with the HPPT it is probable that ceramics such as $\mathrm{Cr}_{2} \mathrm{O}_{3}, \mathrm{Al}_{2} \mathrm{O}_{3}$ are in a plastic state, provided their size is below $50 \mu \mathrm{m}$ while with ICPT bigger ceramic particles can be melted (for alumina up to $120 \mu \mathrm{m}$ for ICPT [7]). A very critical point for the heat and momentum transfer is also the morphology of the particles, better coatings being obtained with dense particles than with agglomerated ones [49 to 52].

Many modelling works have been devoted to the momentum and heat transfer between DC plasma jets (see the general review [47] or [53,54]), including load effect [55]. However the weak point of all these models, beside the uncertainties related to the different transfer coefficients [47], is the introduction of reliable conditions for particle injection.

\section{COATING GENERATION : MICROSCOPIC SCALE}

When spraying with CPT or ICPT, the particles have to be molten upon impact to build a coating with good thermomechanical properties [2,56]. The coating is built particle by particle, the next particle impacting on an already solidified one. Various studies have been devoted to the way the particles splat and they are summarized in [57].They range from a simple classification of the splat shapes such as the one given by Kudinov et al [58] to very sophisticated measurement methods allowing to determine for a single particle its surface temperature and velocity prior to its impact, its temperature and diameter 
evolution during its flattening and the splat temperature evolution during its cooling [59 to 61]. Even when looking at a given point of the substrate (corresponding for example to the mean particle trajectory) the interpretation of the results is not straight forward due to the wide dispersion of the trajectories. However tendencies can be found for the flattening degree (ratio of the splat diameter $D$, assumed to have a disk shape, to that of the initial particle $d$, assumed to be spherical) [62], flattening time, cooling time (from the impacting temperature to about $2000 \mathrm{~K}$ detection limit). The experimental results for the flattening degree are in good agreement with the theoretical work of Hamatani et al $\left(\mathrm{D} / \mathrm{d}=0.83 . \mathrm{Re}^{0.2}\right.$ where $\mathrm{Re}$ is the particle Reynolds number) [63]. As shown by recent results about Zirconia particles [64] $\mathrm{D} / \mathrm{d}$ is more sensitive to particle temperature (varying from 2300 to $4300 \mathrm{~K}$ ) than to its velocity (varying between 100 and $260 \mathrm{~m} / \mathrm{s}$ ). Measurements performed on different substrates [64] have shown that the cooling time and the apparent flattening time depend on the substrate material and decrease with the coating thickness. The cooling time, is strongly linked to the thermal contact resistance between the impacting particle and the substrate which in turn seems to depend on the wettability of the molten droplet. This wettability, for alumina particles $(-45+22 \mu \mathrm{m})$ on steel substrate, depends on the temperature and oxidation of the latter and it controls the splat shape [65]. For example, if close to disk shape splats are obtained at room temperature for particles with $\mathrm{v}<140 \mathrm{~m} / \mathrm{s}$ against splats with torn edges for velocities of $250 \mathrm{~m} / \mathrm{s}$, when the substrate is heated at $250^{\circ} \mathrm{C}$, splats with both velocities have a disk shape and are microcracked all over their surface and exhibit a good adhesion (they are not removed by the diamond tip of the perthometer). Similar results are obtained when the substrate is a flat $(\operatorname{Ra}<0.8 \mu \mathrm{m})$ sprayed alumina coating. Over $270^{\circ} \mathrm{C}$, when the steel substrate starts to be oxidized, torn splats are again obtained. The cooling down of the splat results in a high level of in-plane tensile stress in each splat (called quenching stress $\sigma_{\mathfrak{q}}$ ) which depends on the particle impacting velocity and the substrate temperature (controlling the contact area between the splat and the substrate), on the stress relaxation mechanisms (yielding and creep for metallic splats and microcracks for ceramics) and very little on the substrate nature [66,67]. As these quenching stresses can be fairly high (up to $300 \mathrm{MPa}$ for $\mathrm{NiCr}$ on a substrate at 0.5 times the melting temperature of $\mathrm{NiCr}$ ) they play a crucial role, in the coating thermomechanical properties. When the particles are sprayed on rough surfaces, the flattening degree slightly decreases with the surface roughness increase [61,64], the aspirities of the surface restricting the spread of the material. The roughness modifies the texture of the crystalline structure of the splats, solidification proceeding in multiple directions [61]. It modifies also probably $\sigma_{\mathrm{q}}$, but no study has been yet performed. To study the influence of the trajectory distribution on the splat formation tests derived from the line-scan one [68] can be used. The image analysis of the obtained splats allows to determine, along different vertical or horizontal directions, their size and shape factors versus the substrate nature, temperature and roughness [65]. All these studies are very recent but still many works have to be performed to understand better the microscopic generation of the coating.

When spraying is performed with HPPT, the situation seems completely different with, as already claimed for high velocity oxygen fuel (HVOF) spraying [69], particles impacting in a plastic state or even in a solid state resulting in less oxide in the metallic coatings and stresses supposed to be in compression. However, to our knowledge, no microscopic measurement has been performed in these conditions.

\section{COATING GENERATION : MACROSCOPIC SCALE}

As coatings are generated splat by splat with particles impacting on already solidified ones, they consist of a layered structure (see fig. 1) that is highly anisotropic [71]. The spray parameters affect certain factors of the coatings such as the size and distribution of porosity, oxide content, residual stresses, macro and microcracks, factors which have an important influence on the performance and eventual failure of the coatings. If the molten state of particles upon impact, which depends on the plasma torch design, working conditions, particle injection, size distribution and morphology, plays a great role 
in the coating generation (see the preceedings sections) the temperature control of the coating and substrate before (preheating) during and after (cooling down) is at least as important. The successive passages of the plasma torch induce repeated thermal shocks, which can lead to immediate failure or iterative damage of the coatings. So the temperature distribution within coating and substrate, resulting from the heat fluxes of the plasma and impacting particles [72], from the relative movements torch to

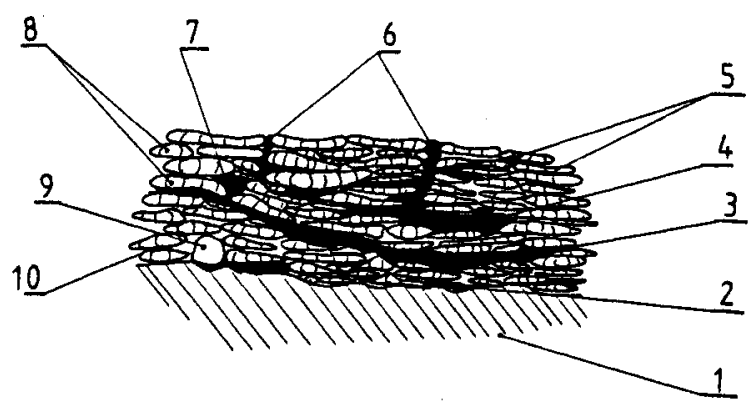

Eig. 1 : Structure of a plasma sprayed coating with all the possible defects (exagerated) : 1 : substrate, $2:$ adhesion defect, $3:$ cohesion defect between two passes, $4:$ cracks parallel to the substrate due to macroscopic residual stresses, $5:$ microcracks within a lamella, $6:$ cracks orthogonal to the substrate and open porosity, $7:$ closed porosity, $8:$ well molten particles : splats, 9 : unmolten particles, 10 : gas inclusion between splats [70].

substrate [73], from the cooling devices, has to be continuously controlled and even better monitored $[74,75]$. However according to the complexity and non linearity of the phenomena involved, the conventional control theory and techniques are not very well suited and thus such processes are good candidates for intelligent control methods such as fuzzy logic [76]. As already seen in the previous section, substrate or previously deposited layers temperature controls the adhesion of the splats lamellae but it also plays a great role in the development of the residual stresses due to expansion mismatch [7779] between substrate and coating or within the coating due to temperature gradients. Unfortunately the coupling of all these parameters is not yet well understood [65] and the coating generation control is still based more on empirical rules than on reliable models.

The development of such models depends on the characterization methods, those reflecting the service failure mode being preferable for engineering design. For example the measurements of adhesion and cohesion of the coatings [80-82] by using pull-off test, shear test, peel test, indentation, scratch test are only useful for ranking purpose, provided the same method is used, because they are sensitive to the presence of flaws. But the development of more rigorous interfacial toughness tests, requires to account for residual stresses present in coatings. However the measurements to account for the residual stresses [77 to 79,83 to 85 ] are by no means always consistent and there is no doubt that the level of experimental error is often very high in the procedures employed. The effects of residual stresses on the debonding of coatings [86] is also not clearly established and a study of the effect of interaction between residual stresses and applied load is still to be done.

The mechanical, thermal, electrical properties of plasma sprayed coatings depend also on the defect structure such as pores and cracks of various sizes, orientation and morphology which arise by many mechanisms [87] not yet well understood. Moreover the measurements of the porosity by different techniques are not directly comparable [88] and many works are still to be done to get a better control of the coatings properties. 


\section{EUTURE}

All materials which are available in a "sprayable" form may be used and they comprise metal, metallic alloys, metallic and nometallic hard materials, hard alloy intermetallics, superalloys and cermets [89]. The wide range of spray materials and manifold combinations with different substrate materials is opening an enormous potential for thermal spraying and particularly plasma spraying which, with its high enthalpy and temperature, allows to spray all the materials. This technology has already gained a strong position on industrial scale in series production. The evolution of the market segmentation of the different thermal spraying processes in USA is given in fig. 2 from [90]. The growth of the thermal spray industry in USA is also very spectacular with $10 \mathrm{M} \$$ in 1960, 150 in 1980, 250 in 1993 and 350 expected in 2000, values excluding coating services representing 1.6 times the value of 1990 [8]. Functionally thermal spray coatings in general and plasma sprayed ones in particular, have been applied as surface coatings [91] and they are used in almost all industries. F.N. Longo has identified applications for thermal spray technology in 34 industrial sectors and a shortened guide is presented in [9] for 12 industrial sectors.

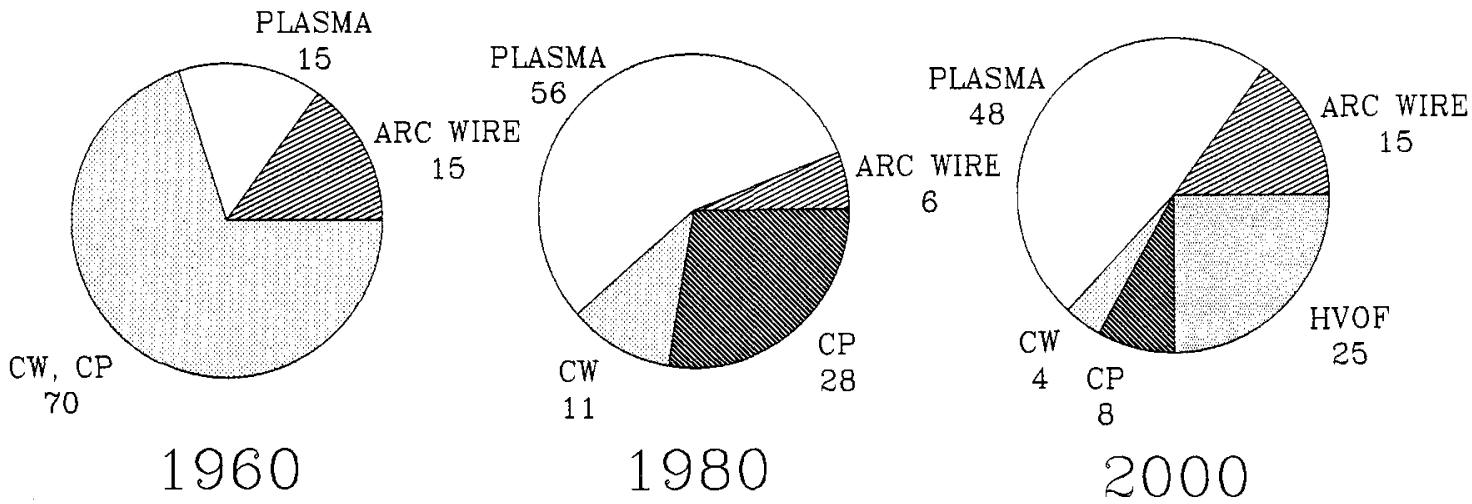

Fig. 2 : Process market segmentation [89].

Beside coatings the production of free standing bodies, especially ceramics, of almost any size with characteristic mechanical and thermomecanical properties is gaining more and more interest in industry [92].

However one of the limitation of the plasma spray coatings development is the cost of the process, especially when a controlled atmosphere chamber has to be used [93]. To limit the costs, torches able to spray a few tens of $\mathrm{kg} / \mathrm{h}$ have been developed and are extensively studied $[6,31,32]$, shroud nozzles are more and more efficient to limit oxydation $[5,40]$ and the quality of the sprayed powders is improved (good flowability, excellent mechanical resistance, high density...) [89] in order to increase the deposition efficiency (for example for $8 \mathrm{wt} \%$ yttria) stabilized zirconia coatings the powder represents about half of the coating price).

Probably one of the key point for the future development of plasma spraying is the improvement of powder technologies widening their potential in combining different materials with extreme differences in their properties [89]. If the different powder fabrication methods are well established some recent refinements are becoming more important such as chemical coating of powder particles and plasma densification prior to spraying [94-96]. Chemical coating allows to establish a stable melt during spraying for example when coating $\mathrm{HfC}$ with $\mathrm{Ni}$ [89]. Plasma powder densification allows to obtain dense spherical particles with a good flowability and reduces the heat propagation phenomenon when using powders combining different materials and prepared by chemical routes, spray drying, mecanofusing... Such processes allow to prepare reactive powders such as for example Fe-Ti-B [95,97] or Fe-Ti-Cu-C [98]. During the powder heating in the plasma jet the synthesis of $\mathrm{TiB}_{2}$ takes place and the 
rapid solidification of the splats results in submicrometer ceramic particles dispersed in a metallic matrix and coatings exhibiting good wear-resistant properties (abrasion and sliding wear). This has also led to the idea of combining self-propagating high temperature synthesis (SHS) with plasma spraying [99] by using the interaction of the components of the conglomerated particles. This has been used for spraying transition metal-non metal refractory compounds $\left(\mathrm{Cr}_{x} \mathrm{C}_{y}, \mathrm{Cr}_{\mathrm{x}} \mathrm{C}_{\mathrm{y}} \mathrm{Si}_{\mathrm{z}}, \mathrm{Ti}_{\mathrm{x}} \mathrm{Si}_{\mathrm{y}}, \mathrm{Ti}_{\mathrm{x}} \mathrm{C}_{\mathrm{y}}, \mathrm{B}_{4} \mathrm{C}, \mathrm{TiB}_{2}, \mathrm{TiN}_{1-\mathrm{x}} \ldots\right)$. The coatings, according to the exothermic reaction of the SHS, have a very good adhesion, an excellent wear resistance and a rather good purity. It is also possible to produce wear-resistant carbide, silicide or nitride reinforced coatings by the so called method "reactive plasma spraying" [100 to 102]. It consists in introducing in a chamber, disposed downstream of the plasma torch, gases containing carbon $\left(\mathrm{CH}_{4}\right.$ for example), nitrogen $\left(\mathrm{NH}_{3} \ldots\right), \mathrm{Si}\left(\mathrm{SiH}_{4} \ldots\right)$ which are heated, dissociated, ionized by the plasma jet. The gases are subsequently brought into contact with heated molten metallic particles and the previously deposited layers at high temperature $\left(800-1000^{\circ} \mathrm{C}\right)$. They react and form dispersed ceramics (TiC, $\mathrm{Si}_{3} \mathrm{~N}_{4}$, $\left.\mathrm{MoSi}_{2} \ldots\right)$ in the sprayed metallic matrix. However, even if very promising, this new method requires still many studies to control the ceramic particles size and their distribution within the coating.

\section{CONCLUSION}

Plasma spraying is one of the most versatile method to apply a wide variety of coatings on almost any substrate. If its development has been mostly empirical it is only since the last decade that new measurement techniques and improvement of modelling have made plasma spray technology to become more a science than an art. Now the heat and momentum transfer between plasma jets and particles are rather well understood and the main problem still pending is to achieve a better control of the particle. injection. Simplified measuring devices to determine particle velocity, flux, surface temperature are under development and they will probably show up in industry within ten years. The study of the plasma jets has made a lot of progress allowing to determine reliable temperature and velocity distributions but showing also that the jets (at least those produced by DC torches) are in fact continuously fluctuating in length and position. The study of these fluctuations, which participate also to the surrounding atmosphere pumping and which effect on particle heating is not yet clearly understood, has promoted researches to limit the plasma jet fluctuations and its mixing with the surrounding air (nozzle shrouds, gas injection to modify the plasma column hot boundary layer, anode nozzles with special design). These works will probably lead to the design of better plasma torches. RF plasma spraying has recently shown its advantage to spray rather big particles $(\sim 100 \mu \mathrm{m})$ to build the metal matrix of composites. High power $(200 \mathrm{~kW})$, high velocity plasma torches allowing to spray a few tens $\mathrm{kg} / \mathrm{h}$ have been designed and the high velocity impacting particles $(>300 \mathrm{~m} / \mathrm{s})$ seem to give dense coatings with compressive residual stresses. However the coating generation is probably the point which requires the most intensive studies. This is made possible by the development of new techniques allowing to follow the impact and temperature history of a single particle. The first results obtained have shown, for conventional plasma torches, the drastic influence on splat formation and adhesion of the substrate and previously deposited layers temperature and roughness. But these studies are still very scarce and for example the influence of the particle velocity and temperature upon impact has not yet been systematically studied. The coating generation as a whole with the influence of temperature gradients and mean temperature during preheating, spraying and cooling down is still not clearly understood for the stress generation and relaxation and the coating cohesion/adhesion. The study of these coupled phenomena is also made more complex by the lack of reliable methods to characterize the coating properties especially methods reflecting the service failure mode. Even if sophisticated measuring devices, computer controlled, have been developed to achieve reliable coatings, they are mostly based on the gained experience and not really on the prediction of the coating properties versus the spray parameters. Moreover they are not well suited for the non linear phenomena involved and intelligent control methods such as fuzzy logic are 
actually studied. Many progresses have been made in powder technology : densification, spheroidization, reactive powders, self propagating high temperature synthesis during spraying. This allows to achieve in situ composite materials with an excellent wear resistance or to synthesize directly carbides, silicides, borides during spraying. Reactive plasma spraying combining thermal plasma CVD and spraying looks also very promising. Such studies are all aimed to reduce the cost of plasma sprayed coatings which is still very high (between 200 and 1600 US\$ $/ \mathrm{kg}$ ) and is probably the greatest limitation to the development of the technology.

\section{REFERENCES}

[1] Thermal spraying, (Pub.) American Welding Society, Miami, Fl USA (1985).

[2] P. Fauchais, A. Grimaud, A. Vardelle, M. Vardelle, Ann. Phys. Fr. 14, 261 (1989).

[3] M. Schoop, Patent DRP 2, 585, 005, Sweden, 49, 270, France 403, 387 and GB 5712.

[4] R.W. Smith, R. Novak, Powder Metallurgy International 23 (3) 147 (1991).

[5] T. Lewis, L. Sokol, E. Hanna, in Thermal Spray, Adv. in Coatings Tech. (Pub.) ASM Int., Oh, USA (1989), p. 149.

[6] T. Morischita, Plasma Technik 2nd Symposium 1, 137 (1991), (Pub.) Plasma Technik, Wohlen, $\mathrm{CH}$.

[7] M.I. Boulos, Journal of Thermal Spray Technolgoy 1 (1) 33 (1991).

[8] G. Jacq, J.P. Durand, Journal of High Temperature Chemical Processes 1 (3) (1993).

[9] F.N. Longo, Journal of Thermal Spray Technology 1 (2) 143 (1992).

[10] K.R. Abram, J. Bustamante, R.D. Etzenhouser, in Thermal Spray Research and Applications, (Pub.) ASM Int. Oh, USA, p. 655 (1991).

[11] S. Bisgaard, in Thermal Spray Research and Applications (Pub.) ASM Int., Oh, USA p. 661 (1991).

[12] P. Fauchais, J.F. Coudert, M. Vardelle, in Plasma Diagnostics, (Pub.) Academic Press, NY, p. 349 (1989).

[13] E. Pfender, J. Fincke, R. Spores, Plasma Chemistry Plasma Processing 1, 529 (1991).

[14] P. Fauchais, J.F. Coudert, M. Vardelle, A. Vardelle, A. Denoirjean, Journal of Thermal Spray Technology 1 (2) 117 (1992).

[15] S.C. Snyder et al., Physical Review E 47 (3) 1996 (1993).

[16] J.R. Fincke, W.D. Swank, D.C. Haggard, in Thermal Spray Coatings : research, design and applications, (Pub.) ASM Int. Oh USA, P. 49 (1993).

[17] J.F. Coudert, M.P. Planche, O. Betoule, M. Vardelle, P. Fauchais, In Thermal Spray Coatings : research, design and applications (Pub.) - ASM Int. Oh USA, p. 19 (1993).

[18] J.R. Fincke, S.C. Snyder, W.D. Swank, "Comparison of enthalpy probe and laser light scattering measurement of thermal plasma temperatures and velocities" accepted in Rev. Sci. Instrum..

[19] E. Pfender, Plasma jet behavior and modeling associated with the plasma spray process Inter. Conf. on Metallurgical Coatings and Thin Films, San Diego, April 1993.

[20] P. Roumilhac, M. Vardelle, A. Vardelle, P. Fauchais, in Thermal Spray Technology New Ideas and Processes (Pub.) ASM Int. Oh. USA p. 111 (1989).

[21] B. Pateyron, M.F. Elchinger, G. Delluc, P. Fauchais, Plasma Chemistry Plasma Processing 12 (4) 421 (1992).

[22] B. Pateyron, G. Delluc, M.F. Elchinger, P. Fauchais, High Temperature Chemical Processes 1 (3) 325 (1992).

[23] M. Vardelle, A. Vardelle, P. Roumilhac, P. Fauchais, in Thermal Spray Technology, New ideas and Processes (Pub.) ASM Int., Oh USA, p. 117 (1989).

[24] J.F. Brilhac, B. Pateyron, J.F. Coudert, P. Fauchais, P. Pasquini, A. Bouvier, Journal of High Temperature Chemical Processes 3 (1) 421 (1992). 
[25] M.F. Zhukov, Basical calculations of plasmatrons, Academy of Sciences of USSR Siberian Branch, (Pub.) Nauka Novossibirsk (1975).

[26] T. Benecki, in Thermal Spray : Advances in Coatings Technology (Pub.) ASM Int. Oh, p. 63 (1988).

[27] S. Russ, E. Pfender, J. Heberlin, in Thermal Spray Coatings : research design and applications, (Pub.) ASM Int. Oh USA p. 97 (1993).

[28] A.H. Dilawari, J. Szekely, R. Westoff, Plasma Chemistry Plasma Processing 2, 291 (1989).

[29] J.D. Ramshav, C.H. Chang, Plasma Chem. Plasma Proc. 12299 (1992).

[30] M. Vardelle, A. Vardelle, I. Saray, P. Fauchais, Comparison of classical and axial injection torches to spray alumina coatings, accepted in Materials and Manufacturing Processes.

[31] P. Chvaska and M. Harabovsky, in Thermal Spray : International Advances in Coatings Technology (Pub.) ASM Int. Oh USA, p. 81 (1992).

[32] F. Uchiyama et al., in Thermal Spray : International Advances in Coatings Technology (Pub.) ASM Int. Oh USA, p. 105 (1992).

[33] J.R. Fincke, C.L. Jefferey, in Thermal Spray Technology. New ideas and processes (Pub.) ASM Int. Oh, USA p. 55 (1989).

[34] A. Bunya et al. in Thermal Spray : International Advances in coatings technology (Pub.) ASM Int., Oh, USA p. 92 (1992).

[35] H. Marno, Y. Harata, J. Kato, Int. Thermal Spray Conf. London UK - 4-9 June (1989) (Pub.) Welding Institute, London, GB.

[36] J. Jurewicz, M.I. Boulos, in Thermal Spray Coatings : research, design and applications, (Pub.) ASM Int. Oh. USA p. 89 (1993).

[37] P.J. Meyer, in Thermal Spray Research and Applications, (Pub.) ASM Int. Oh USA p. 99 (1991).

[38] R.A. Neiser, R.C. Dykkulzen, M.F. Smith, K.J. Hollis, in Thermal Spray Coatings : research, design and applications, (Pub.) ASM Int. Oh USA p. 61 (1993).

[39] W. Malliner, D. Stover, in Thermal Spray Coatings : research, design and applications, (Pub.) ASM Int. oh USA p. 291 (1993).

[40] Y. Borisov et al., 2nd Plasma Technik Symposium 1, 161 (1991) (Pub.) Plasma Technik, Wohlen, $\mathrm{CH}$.

[41] O. Betoule, G. Soucy, P. Fauchais, M.I. Boulos, M. Ducos, International Advances in Coatings Technology (Pub.) ASM Int. Oh USA, p. 105 (1992).

[42] P. Sakov, R. Raghuraman, in Thermal Spray Coatings : research, design and applications, (Pub.) ASM Int. Oh USA p. 369 (1993).

[43] E. Lugsheider, I. Rass, in Thermal Spray Coatings : research, design and applications, (Pub.) ASM Int. Oh USA p. 329 (1993).

[44] W.D. Swank, J.R. Fincke, D.C. Haggard, in Thermal Spray Coatings : research, design and applications, (Pub.) ASM Int. Oh USA p. 25 (1993).

[45] M. Vardelle, A. Vardelle, P. Fauchais, Journal of Thermal Spray Technology $2 \underline{2}$ (1) 79 (1993).

[46] W.C. Roman, W. Winter, A.A Rotunno, K. Fessenden, W. Willer, in Thermal Spray Research and Applications, (Pub.) ASM Int. Oh. USA, p. 49 (1991).

[47] M. Boulos, P. Fauchais, E. Pfender, M. Vardelle, Fundamentals of plasma particle momentum and heat transfer in Thermal Spraying, (Pub.) World Scientific (1993).

[48] J.M. Leger, P. Fauchais, A. Grimaud, M. Vardelle, A. Vardelle, B. Pateyron, in Thermal Spray International Advances in Coatings Technology, (Pub.) ASM Int. Oh USA p. 17 (1992).

[49] M. Vardelle, A. Vardelle, A. Denoirjean, P. Fauchais, Mater. Res. Soc. Symp. Proc. (Pub.) MRS Pittsburgh, Pn, USA, 190175 (1991).

[50] A. Denoirjean et al in Thermal Spray : International Advances in Coatings Technology (Pub.) ASM Int. Oh USA, p. 967 (1992). 
[51] S. Dallaire, G. Cliche, Journal of Thermal Spray Technology 2 (1) 39 (1993).

[52] B. Kolman, J. Forman, J. Dubsky, P. Chraska, in Thermal Spray Coatings : research, design and applications, (Pub.) ASM Int. Oh USA p. 353 (1993).

[53] C.H. Chang, in Thermal Spray : Int. Advances in Coatings Technology Conf. Orlando (Pub.) ASM Int. Oh USA, p. 793 (1992).

[54] O.P. Sololenko, S.M. Gelfand, A.L. Sorokin, A.P. Zinoviev, in Thermal Spray Coatings : research, design and applications, (Pub.) ASM Int. Oh USA p. 793 (1993).

[55] A. Vardelle, M. Vardelle, P. Fauchais, P. Proulx, M.I. Boulos, in Thermal Spray : Int. Advances in Coatings Technology Orlando (Pub.) ASM Int. Oh, USA, p. 543 (1992).

[56] J.H. Zaat, Ann. Rev. Mater. Sci. 13, 9 (1983).

[57] A. Vardelle, M. Vardelle, P. Fauchais, Pure and Applied Chemistry 64 (5) 637, 1992.

[58] V.V. Kudinov, P. Yu Pekshev, U.A. Safiullin, in High Temp. Dust Laden Jets, p. 381 (1989) (Pub.) VSP, NL.

[59] C. Moreau, P. Cielo, M. Lamontagne, S. Dallaire, M. Vardelle, Meas. Sci. Technol. 1, 807 (1990).

[60] S. Fantassi, M. Vardelle, P. Fauchais, C. Moreau, in Thermal Spray : International Advances in Coatings Technology (Pub.) ASM Int., Oh. USA p. 755 (1992).

[61] C. Moreau, P. Cielo, M. Lamontagne, Journal of Thermal Spray Technology 1 (4) 317 (1992).

[62] S. Fantassi, M. Vardelle, A. Vardelle, P. Fauchais, "Influence of the velocity of plasma sprayed particles on splat formation". Accepted in Journal of Thermal Spray Technology.

[63] H. Hamatani, T. Okada, T. Yoshida, Proc. ISPC 931527 (1991) (Ed.) R. d'Agostino, Univ. of Bari, Italy.

[64] S. Fantassi, M. Vardelle, A. Vardelle, A. Denoirjean, P. Fauchais, "Relationships between particle parameters on impact and flattening process during plasma spray deposition" to be published in the proceedings of ISPC 11 to be held at Loughborough GB Aug. (1993).

[65] L. Bianchi, M. Mellali, A. Grimaud, P. Fauchais, P. Lucchese, "How to control substrate and coating temperature during spraying to enhance the adhesion of alumina coatings", to be published in the proc. of ISPC 11 to be held at Loughborough GB, Aug. (1993).

[66] S. Kuroda, T.W. Clyne, Thin Solid Films 200, 49 (1991).

[67] S. Kuroda, T. Fukushima, S. Kitahara, Journal of Thermal Spray Technology 1 (4) 325 (1992).

[68] K.A. Roberts, T.W. Clyne, Surface and Coatings Technology 41, 103 (1990).

[69] J.A. Browning, Journal of Thermal Spray Technology 1 (4) 289 (1992).

[70] L. Pawlowski, State Thesis, University of Limoges, June (1985).

[71] R. Mc Pherson, Surf. Coat. Techn. (39/40) 173 (1989).

[72] F. Monerie-Moulin, F. Gitzhofer, P. Fauchais, M. Boulos, A. Vardelle, J. of High Temp. Chemical Processes 1 (3) 249 (1992).

[73] D. Bernard, P. Fauchais, in Thermal Spray Research and Applications (Pub.) ASM Int. Oh. USA p. 551 (1991).

[74] M. Mellali, P. Fauchais, A. Grimaud, Journal of High Temp. Chemical Processes 1 (3) 195 (1993).

[75] P. Lucchese, J.F. Salin, J. Blot, J. Castagnes, in Thermal Spray Coatings : Research Design and Applications, (Pub.) ASM Int. Oh. USA p. 231 (1993).

[76] L.J. Einerson, D.E. Clark, B.A. Detering, P.L. Taylor, in Thermal Spray Coatings : Research, Design and Applications, (Pub.) ASM Int. Oh. USA p. 205 (1993).

[77] M.K. Hobbs, H. Reiter, Surf. Coat. Technology 34, 33 (1988).

[78] S.C. Gill, T.W. Clyne, Met. Trans. 21B, 377 (1990).

[79] S.C. Gill, T.W. Clyne, 2nd Plasma Technik Symposium 1, 277 (1991) (Pub.) Plasma Technik Wohlen $\mathrm{CH}$. 
[80] C.C. Berndt, C.K. Lin, Measurement of adhesion for thermally sprayed materials to be published in J. Adhesion Sci. and Techn..

[81] S.J. Howard, A.J. Philipps, T.W. Clyne, Composites 24(2) 103 (1993).

[82] D.S. Rickerby, Surf. Coat. Techn. 36, 541 (1988).

[83] R. Elsing, O. Knotek, U. Balting, Surf. Coat. Technol. 41, 147 (1990).

[84] M.F. Gruninger et al., J. Am. Ceram. Soc. 70, 344 (1987).

[85] S. Kuroda, T. Kukushima, S. Kitahara, Thin Solid Films 164, 157 (1988).

[86] M.D. Drory, M.D. Thouless, A.G. Evans, Acta Metall. 36, 2019 (1988).

[87] P. Yu Pekshev, V.A. Safinlin, Porosity of plasma sprayed alumina in High Temperature DustLaden Jets in Plasma Technology (Pub.) V.P.S. Utrecht, NL p. 437 (1990).

[88] J. Ilarsky et al., in Thermal Spray Coatings : Research, Design and Applications (Pub.) ASM Int. Oh. USA p. 505 (1993).

[89] E. Lugsheider, H. Eschnauer, U. Müller, Th. Webec PMI 23 (1) 33 (1991).

[90] M. Thorpe, Hobart Tafa Technologies Conference presented at the plenary session of NTSC 93 Annaheim Ca June (1993).

[91] R.W. Smith, R. Novak, PMI 23 (3) 147 (1991).

[92] E.H. Lutz, PMI 25 (3) 131 (1993).

[93] G. Jacq, .P. Durand, Journal of High Temperature Chemical Processes 1 (3) 57 (1992).

[94] A. Denoirjean et al., in Thermal Spray : International Advances in Coatings Technology (Pub.) ASM Oh.USA p. 975 (1992).

[95] S. Dallaire, Journal of Thermal Spray Technology 1 (1) 41 (1992).

[96] E. Lugsheider, I. Rass, in Thermal Spray Coatings : Research, Design and Applications (Pub.) ASM Int. Oh. USA, p. 335 (1993).

[97] B. Champagne, S. Dallaire, J. Vac. Sci. Technology A3 (6) 2373 (1985).

[98] J.G. Legouse, S. Dallaire, in Thermal Spray Coatings : Research, Design and Applications (Pub.) ASM Int. Oh. USA p. 429 (1993).

[99] Y. Borisov, A. Borisova, in Thermal Spray Coatings : Research, Design and Applications (Pub.) ASM Int. Oh. USA p. 139 (1993).

[100] R.W. Smith, PMI 25 (3) 9 (1993).

[101] R.W. Smith, Z.Z. Mutasim, Journal of Thermal Spray Technology 1 (1) 57 (1992).

[102] R.W. Smith et al., in Thermal Spray Coatings : Research, Design and Applications (Pub.) ASM Int. Oh. USA p. 439 (1993). 